\title{
Green designing of solar hot water systems using computer simulations
}

\author{
Agnieszka Żelazna, ${ }^{1, *}$, Artur Pawłowski ${ }^{1}$, and Agata Zdyb ${ }^{1}$ \\ ${ }^{1}$ Lublin University of Technology, Faculty of Environmental Engineering, Nadbystrzycka 40B, 20-618 Lublin, Poland
}

\begin{abstract}
Solar thermal installations are one of the popular types of renewable energy sources. This paper presents the comparison of the considered design variants of the typical solar hot water installation on the basis of Life Cycle Assessment. The simulations and the design criteria included:- optimal angle of inclination and orientation of collectors for the selected location (simulations in GetSolar),- optimal type of collectors (simulations in SimaPro).Life cycle analysis of solar hot water systems shows that this technology has the potential to reduce the environmental impact of hot water preparation while compared to the conventional energy sources. However, the optimisation criteria used for green designing in the life cycle perspective can significantly improve the environmental balance of the analysed technologies.
\end{abstract}

\section{Introduction}

In the recent years, the concept of sustainability has become the common interest of various disciplines. The explanation for this popularity is the need to perform the sustainable development in our economy, society and environment. It is of fundamental meaning to all because it deals with the continued existence of human and other species on the planet [1].

Sustainable development in the area of buildings means constructing structures and using systems that are environmentally responsible and resource-efficient through the various stages of a building life-cycle [2,3]. Green designing is focused on actions aimed at environmental improvement of products during the initial phase of its life, based on selection of materials or products with lower environmental impact, application of alternative processes, improvement in logistics and building processes, etc. [3].

One of the major rules in green designing of buildings is the use of alternate power sources such as solar or wind power [1]. However, the introduction of new technologies to the market should always be accompanied by an analysis of their environmental impact. Solar thermal installations designed as a source of hot water can be performed with the use of several types of collectors, installation materials and locations.

The crucial question in the case of green designing is the meaning of "green". Interpreted as minimisation of environmental burdens, it can be performed with the use of several methods of environmental assessment. While talking about the entire life cycle, the method that considers all the inputs from the environment, as well as the accompanying emissions, is Life Cycle Assessment with the broad range of Life Cycle Impact Assessment techniques.

\section{Studies on clean energy}

A variety of research papers have been devoted to the subject of clean energy, including studies on the environmental Life Cycle Assessment of devices and energy systems [4-7]. Among them, numerous analyses concern the subject of environmental assessment of renewable energy sources $[10,11]$, as well as the development of new production techniques [12-14]. Most of the analyses concern the ecological balance of hot water preparation systems on the examples of devices operating in Southern Europe, or only include Life Cycle Assessment at the stage of system components production.

In the work of Ardente et al. (2005), the Life Cycle Assessment method was used to determine the total carbon dioxide emission associated with the production phase of a flat plate collector with an effective area of $2.13 \mathrm{~m}^{2}$. The author calculated the use of primary energy in the module production phase as $11.5 \mathrm{GJ}$ and the emission of carbon dioxide from this phase as 721 $\mathrm{kgCO}_{2 \mathrm{eq}}$. The majority of primary energy is associated with pre-production, i.e. the stage of extracting raw materials. In summary, attention was paid to the fact that the direct energy consumption is lower than indirect consumption, and thus most emissions are related to the raw material extraction phase [15].

Kalogirou applied the Life Cycle Assessment method to determine the environmental impact of flat solar collectors from the point of view of primary energy consumption in the production phase. The first system analysed by the author operated as an integrated system with hot water storage. The use of primary energy for the production of system components was estimated as 2.7 GJ [16]. For the next system with two media:

${ }^{*}$ Corresponding author: a.zelazna@ pollub.pl 
polypropylene glycol and water, the author calculated the primary energy consumption as 3.5 GJ [17].

Battisi and Corrado analysed the thermal solar collector system integrated with the hot water storage tank in the perspective of the life cycle. The use of primary energy for the production, supply and final management of the tested system was calculated as 3.1 $\mathrm{GJ}$, and greenhouse gas emissions as $219.4 \mathrm{kgCO}_{2 \text { eq }}$. The share of the system's production phase in the total value of the indicator was $97.8 \%$. Due to the specific design of the system (a capacitive collector as a heat tank), which does not require a pump, the operational phase of the life cycle was omitted. It should be noted that this type of installation is intended for the locations in Southern Europe or equivalent regions. Under the conditions of the Polish climate, due to the possibility of freezing in the winter season, the system should not be used, or a seasonal emptying of the installation should be conducted [18].

According to the current state of knowledge, the majority of renewable sources can be treated as a source of clean, green energy, however it is significant to consider the issues of their location individually. While using energy of wind, sun or water, one should remember about the changing local climate conditions and adapt the design solutions to the individual needs of the recipients.

\section{Comparison of solar systems as an example of green designing}

\subsection{Assumption for analysis}

The study on green performance of system design was carried out on the basis of typical solution for singlefamily house with four occupants. Hot water consumption was estimated as $180 \mathrm{l} / \mathrm{d}$, while the hot water tank capacity was 2001 and piping length equalled $25 \mathrm{~m}$.

The selected location (Lublin, Poland) is characterised by favourable insolation conditions while compared to the other regions of Poland, with yearly solar irradiance $1047.27 \mathrm{kWh} / \mathrm{m}^{2}$.

Two types of solar thermal collectors were tested:

- flat plate collector with Al-Cu absorber - System 1:

optical efficiency $\mathrm{n} 0=0.751[-]$,

- $\quad 1^{\text {st }}$ order heat loss coefficient a $1=4.999\left[\mathrm{~W} / \mathrm{m}^{2}\right]$,

- $\quad 2^{\text {nd }}$ order heat loss coefficient a $2=0.011\left[\mathrm{~W} / \mathrm{m}^{2}\right]$

- heat-pipe collector - System 2:

- $\quad$ optical efficiency n $0=0.74[-]$,

- $\quad 1^{\text {st }}$ order heat loss coefficient a $1=1.28\left[\mathrm{~W} / \mathrm{m}^{2}\right]$,

- $\quad 2^{\text {nd }}$ order heat loss coefficient a2 $=0.007\left[\mathrm{~W} / \mathrm{m}^{2}\right]$.

\subsection{Materials and methods}

For a comprehensive implementation of the green design concept, computer modelling was done in two applications (GetSolar and SimaPro). The first program was used to choose the favourable orientation and optimal angle of inclination for the selected collectors. The second one, SimaPro, was used for the modelling of system components and their life cycle.

As the life cycle has an impact on the assessment method, Eco-indicator'99 was used. In this damage- oriented method, the calculations concerning total environmental load expressed in Points of Ecoindicator were conducted on the basis of detailed life cycle inventory. The higher the indicator, the greater the environmental impact. It should be mentioned that this indicator is used mostly for comparisons of products or systems, since the absolute value of points is not very relevant.

The calculations were made throughout the midpoint level, including three damage categories (Human Health, Ecosystem Quality, Resources) and eleven impact categories (Fossil fuels, Minerals, Land use, Acidification/eutrophication, Ecotoxicity, Ozone layer, Radiation, Climate change, Respiratory inorganics, respiratory organics, and Carcinogens).

In the selected method, the damage in Human Health includes the effects of climate change, ozone layer depletion, radiation and other pollutants (excluding noise and some respiratory effects of heavy metals) on the decrease in the lifespan and increase in incidence of illnesses. The damage category Ecosystem Quality is based on the measurable effects of environmental burdens (including processes of acidification, eutrophication, land transformation and toxic pollutants) on the lower diversity of species. In the category Resources, the surplus energy necessary for the future exploitation of minerals and fossil fuels from unfavourable geological conditions is included. Conversion of the categorised indicators into a single indicator requires a weighing procedure, which was carried out on the basis of an egalitarian model [19].

In order to avoid the mistake connected with the data uncertainty of the proposed model, an additional analysis was carried out using Monte Carlo statistical simulations. This analysis, based on the series of random samples, was intended to indicate the probability of an inverted result due to a statistical error in the model input data.

All the operations connected with environmental data modelling as well as the calculations (Ecoindicator'99 and Monte Carlo) were conducted in Sima Pro v. 7.

\subsection{Results of GetSolar modelling}

GetSolar is one of the computer programs enabling easy and time-saving modelling of solar systems power output.

The parameters needed for the model include:

- Technical data on collector performance:

- optical efficiency n0 [-],

- $1^{\text {st }}$ order heat loss coefficient a1 $\left[\mathrm{W} / \mathrm{m}^{2}\right]$,

- $\quad 2^{\text {nd }}$ order heat loss coefficient a2 $\left[\mathrm{W} / \mathrm{m}^{2}\right]$, collector area $\left[\mathrm{m}^{2}\right]$.

- Climate data on daily temperatures and solar irradiance on collector plane $\left[\mathrm{W} / \mathrm{m}^{2}\right]$.

- Type of solar system (single, combined, etc.) and capacity of hot water tank [1].

- Orientation and angle of inclination $\left[{ }^{\circ}\right]$.

Among the mentioned, the collector area, orientation and inclination, type of materials, capacity of hot water tank are variables. The rest of data were assumed after producers of collectors (technical data), and as typical design parameters. Two of the variables (orientation and 
angle of inclination) were examined to provide the information about possible energy output, efficiency and the coverage of demand on hot water during one year of installation operation.

The results of possible energy output modelling are presented in Table 1 and Table 2.

Table 1. The possible energy output, efficiency and hot water demand coverage modelled for system 1 .

\begin{tabular}{|c|c|c|c|c|}
\hline 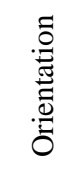 & 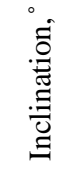 & 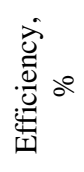 & 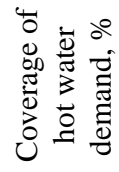 & 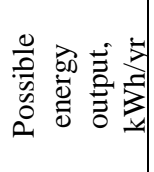 \\
\hline \multirow{3}{*}{ SE } & 30 & 28 & 43 & 1481 \\
\hline & 45 & 28 & 42 & 1467 \\
\hline & 60 & 28 & 40 & 1393 \\
\hline \multirow{3}{*}{ S } & 30 & 28 & 46 & 1590 \\
\hline & 45 & 29 & 46 & 1608 \\
\hline & 60 & 29 & 44 & 1534 \\
\hline \multirow{3}{*}{ SW } & 30 & 29 & 44 & 1540 \\
\hline & 45 & 29 & 45 & 1554 \\
\hline & 60 & 30 & 44 & 1509 \\
\hline
\end{tabular}

Table 2. The possible energy output, efficiency and hot water demand coverage modelled for system 2 .

\begin{tabular}{|c|c|c|c|c|}
\hline 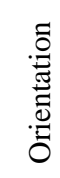 & .0̊ే & 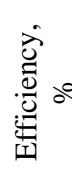 & 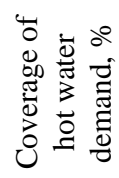 & 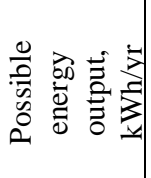 \\
\hline \multirow{3}{*}{ SE } & 30 & 43 & 59 & 2049 \\
\hline & 45 & 44 & 59 & 2040 \\
\hline & 60 & 45 & 56 & 1957 \\
\hline \multirow{3}{*}{ S } & 30 & 44 & 62 & 2148 \\
\hline & 45 & 45 & 62 & 2175 \\
\hline & 60 & 46 & 61 & 2121 \\
\hline \multirow{3}{*}{ SW } & 30 & 44 & 60 & 2049 \\
\hline & 45 & 45 & 60 & 2102 \\
\hline & 60 & 46 & 59 & 2043 \\
\hline
\end{tabular}

The results presented in Table 1 and Table 2 show the strong dependence between energy output and analysed variables. The analysed parameters were assumed as the typical for selected location of systems, excluding East and West orientation. With only South, South-East and South-West orientation, and the angle of inclination between $30^{\circ}$ and $60^{\circ}$, the decrease in possible energy output reached $13,4 \%$ yearly for System 1 and $10 \%$ yearly for System 2, which means that System 1 was more sensitive to changes in location.

While compared to System 1, System 2 is characterised by higher efficiencies (average difference equals 16\%) and therefore $16 \%$ (av.) higher coverage of hot water demand. The difference in results from the type and surface of collectors were taken into consideration.

\subsection{Results of SimaPro modelling}

SimaPro as one of Life Cycle Assessment tools enabled the comparison between the assumed life cycle of
System 1 and System 2, considering the related environmental burdens.

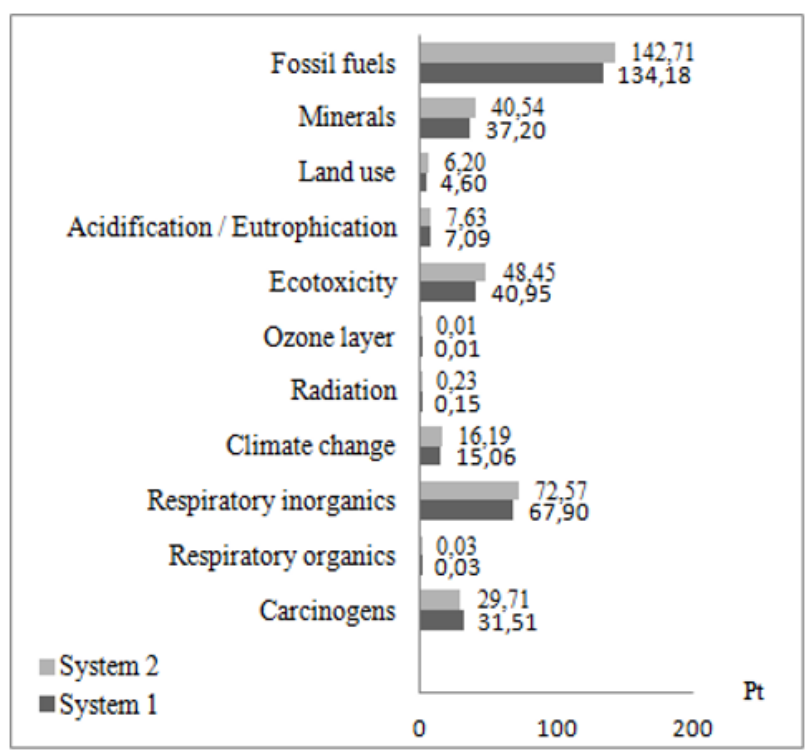

Fig. 1. Impact assessment results for System 1 and System 2.

On the basis of the detailed inventory, including production, operation and final disposal of System 1 and System 2, the environmental impact was assessed using the method of Ecoindicator'99. The results of systems comparison at the stage of impact assessment are presented in Figure 1.

The single score calculated for System 1 is equal $338.7 \mathrm{Pt}$, while for System 2 it is $364,3 \mathrm{Pt}$. The uncertainty analysis by Monte Carlo method shows the zero probability of the adverse situation (result for System 2 < System 1), while it may happen that some differences occur in the single impact categories (Respiratory organics, Carcinogens, Minerals, Land Use). The only damage category with non-zero probability $(0,4 \%)$ of getting the reverse result was Human Health.

The total number of simulation runs was equal 1000 , with standard error of mean equal 0.01 and confidence interval $95 \%$. The mean value of the difference between results obtained for System 1 and System 2 was equal $26 \mathrm{Pt}$ and median $-25,6 \mathrm{Pt}$.

At the stage of damaged assessment, the trend of higher values corresponding to System 2 persists, with the exception of one category (Carcinogens). The highest values of indicators are in both cases related to categories Fossil fuels and Respiratory inorganics, which is connected with the use of the conventional energy sources at the stage of production and operation of systems, especially for the supply of pumps and control devices.

While transformed into the functional unit ( $1 \mathrm{kWh}$ of the possible energy output during 20 years of operation), the obtained results, which are presented in Table 3, equal:

- From 10.63 to $12.16 \mathrm{mPt} / \mathrm{kWh}$ (depending on selected orientation and inclination) for System 1.

- From 8.37 to $9.31 \mathrm{mPt} / \mathrm{kWh}$ (depending on selected orientation and inclination) for System 2. 
Table 3. Ecoindicator per functional unit, $\mathrm{mPt} / \mathrm{kWh}$.

\begin{tabular}{|c|c|c|c|}
\hline Orientation & Inclination, $^{\circ}$ & $\begin{array}{c}\text { System 1, } \\
\mathrm{mPt} / \mathrm{kWh}\end{array}$ & $\begin{array}{c}\text { System 2, } \\
\mathrm{mPt} / \mathrm{kWh}\end{array}$ \\
\hline \multirow{3}{*}{$\mathrm{SE}$} & 30 & 11,43 & 8,89 \\
\cline { 2 - 4 } & 45 & 11,54 & 8,93 \\
\cline { 2 - 4 } & 60 & 12,16 & 9,31 \\
\hline \multirow{3}{*}{$\mathrm{S}$} & 30 & 10,65 & 8,48 \\
\cline { 2 - 4 } & 45 & 10,53 & 8,37 \\
\cline { 2 - 4 } & 60 & 11,04 & 8,59 \\
\hline \multirow{3}{*}{ SW } & 30 & 11,00 & 8,89 \\
\cline { 2 - 4 } & 45 & 10,90 & 8,66 \\
\cline { 2 - 4 } & 60 & 11,22 & 8,92 \\
\hline
\end{tabular}

The comparison of results referred to the functional unit shows that the phase of operation, especially the possible energy output, is the most meaningful element of the life cycle of selected systems. System 2, with better efficiency, is characterised by lower value of Ecoindicator per functional unit, in spite of the fact that its single score was higher.

At the same time, the location-related differences between the minimal and maximal values of indicators per functional unit reach $15 \%$, which prove the important role of designers in the management of solar systems life cycle.

\section{Conclusion}

The concept of green designing is strongly related to environmental analysis. Still, as it was shown in this paper, not only the environmental studies are the important issue. The role of the designers, engineers and architects is no less significant, which has to be concluded on the basis of $15 \%$ differences between the environmental assessment of the same system with different design of location. With a functional unit defined as the unit of the system energy output, the value of yield becomes an important factor.

Studies on solar thermal technologies show that this type of renewable energy source meets the requirements of sustainable energy by providing access to energy with a relatively low level of the environmental impact, increasing energy independence, raising the standard of living and the developing the labour market. The use of clean energy to supply pumps and system controllers can contribute to the reduction of the impact associated with the use of electricity.

The application of Life Cycle Assessment in the case of energy systems is aimed at extending knowledge of their designers, users and potential investors about the chosen technology. This promotes the decision to replace conventional technologies with modern, ecological solutions, and thus to reduce emissions to the environment and reduce the level of fossil fuel consumption. The management of production processes within the use of Life Cycle Assessment can also contribute to the selection of potentially green materials and energy sources. These are important issues not only from the perspective of environmental protection, but also health and comfort of human life, which, with the fulfilment of economic capability conditions, constitutes the basis for qualifying solar systems as meeting the criteria of sustainable development.

This research work was supported from statutory founds of Faculty of Environmental Engineering, Lublin University of Technology.

\section{References}

1. A. Ragheb, H. El-Shimy, G. Ragheb, Proc. Soc. Beh. Scienc. 216, 778-787 (2016)

2. A. Żelazna, A. Pawłowski, Env. Eng. 3825 (2011)

3. I. Zbicinski, J. Stavenuiter, B. Kozlowska and H.P.M. van de Coevering, Product Design and Life Cycle Assessment (The Baltic University Press, Uppsala 2006)

4. E. Zambolin, D. Del Col, Sol. En. 84(8), 1382-1396 (2010)

5. G. Gaidajis, K. Angelakoglou, Jour. of Eng. Sc. and Techn. Rev. 4 (1), 92-95 (2011)

6. A.Varun, I.K. Bhat, R. Prakash, Renew. Sust. Energ. Rev. 13, 1067 (2009)

7. M.J. Wild-Scholten, E.A. Alsema, Mater. Res. Soc. Symp. Proc., 895-904 (2006)

8. S. Kalogirou, Sol. Energy 83, 39-48 (2009)

9. G. Tsilingiridis, G. Martinopoulos, N. Kyriakis, Renew. Energ. 29, 1277-1288 (2004)

10. J. Gołębiowska, T. Cholewa, A. Raczkowski, A. AIP Conf. Proc. 1988-2040 (2018)

11. A. Duda, J. Gołębiowska., A. Żelazna, Probl. Ekorozw. 11 (1), 177-180 (2016)

12. J. Gołębiowska, Inform. Autom. Pom. w Gosp. i Ochr. Środ. 5 (3), 71-78 (2015)

13. A. Czechowska-Kosacka, W. Cel, J. Kujawska, K. Wróbel, Roczn. Ochr. Środ. 17(1), 246-255 (2015)

14. S. Gułkowski, J. M. Olchowik, Roczn. Ochr. Środ. 15 (1). 436-447 (2013)

15. F. Ardente, G. Beccali, M. Cellura, V. Lo Brano, Renew. Energ. 30, 1031-1054 (2005)

16. S. Kalogirou, , Environmental benefits of domestic solar energy systems, Energ. Convers. Manage. 45, 3075-3092 (2004)

17. S. Kalogirou, Y. Tripanagnostopoulos, M. Souliotis, Energ. Buildings 37 (8), 824-835 (2005)

18. R.G. Battisti, A. Corrado, J. Clean. Prod 13, 12951300 (2005)

19. A. Żelazna, Rocz. Ochr. Środ. 15 (1), 258-271 (2013). 